\title{
Proceeding
}

Supplementary Issue: Spring Conferences of Sports Science. Costa Blanca Sports Science Week, 26-28 April 2018. Calpe. Alicante, Spain

\section{Bioelectric activity of the brain and the predictive importance of effects of neurobiofeedback course at athletes}

\author{
LARISA CHERAPKINA
}

Department of Anatomy, Physiology, Sport Medicine and Hygiene, Siberian State University of Physical Education and Sport, Russia

\begin{abstract}
Works of the last years show activity of scientists on introduction of neurobiofeedback training in process of athletes training. At the same time, authors emphasize the need of further carrying out researches for this field of knowledge, first of all, caused by insufficiency of empirical data. The purpose of work was identification of athletes' brain features of bioelectric activity, and determination of the importance of neurobiofeedback effects in effectiveness forecasting of their competitive activity. With 101 athletes the neurobiofeedback course directed to increase in power of EEG in the alpha range by means of a hardware and software system of "BOSLAB-ALFA" was conducted. Prior to a training and after its termination by means of the 19-channel electroencephalograph "Neuron Range 3" "background" EEG registered. After a neurobiofeedback course the effectiveness of competitive activity at each athlete which was considered as successful was estimated if exceeded the result received at the same rank previous competitions. The statistical analysis of the obtained data was carried out by means of software packages of "StatPack" and "SPSS 13". Results of the conducted research have allowed to distinguish the peculiar " the athlete's encephalographic portrait" which is characterized by more expressed activity in a theta - and delta ranges, the insufficient relative power of brain bioelectric activity in the alpha range. And also to establish the informative indicators of post-training changes of EEG determining distinctions by success of competitive activity with an accuracy of recognition of $100 \%$. Keeping EEG the signs characteristic of women, sportswomen differ from sportsmen in set of post-
\end{abstract}

\footnotetext{
Corresponding author. Department of Anatomy, Physiology, Sport Medicine and Hygiene, Siberian State University of Physical Education and Sport, 644009, Maslennikova, 144, c. Omsk, Russia.

E-mail: kochelab@mail.ru

Supplementary Issue: Spring Conferences of Sports Science. Costa Blanca Sports Science Week, 26-28 April 2018. Calpe. Alicante, Spain.

JOURNAL OF HUMAN SPORT \& EXERCISE ISSN 1988-5202

(c) Faculty of Education. University of Alicante

doi: 10.14198/jhse.2018.13.Proc2.21
}

S370 | 2018 | Proc2 | VOLUME 13

C 2018 University of Alicante 
training predictors of success of competitive activity. Key words: ATHLETES, BIOFEEDBACK, EEG, SUCCESS OF COMPETITIVE ACTIVITY.

\section{Cite this article as:}

Cherapkina, L. (2018). Bioelectric activity of the brain and the predictive importance of effects of neurobiofeedback course at athletes. Journal of Human Sport and Exercise, 13(2proc), S370-S384. doi:https://doi.org/10.14198//hse.2018.13.Proc2.21 


\section{INTRODUCTION}

Modern sports activity demands achievement of a limit of human opportunities and places extremely great demands on mentality and a functional condition of athletes (Tregubova and Tarasov, 2014; Kraynova and Berdichevskaya, 2013).

For achievement of the goals and the solution of objectives various methods of self-control are actively used. The most effective of them is the neurobiofeedback (Blumenstein and Orbach, 2014) which is based on physiological mechanisms, promoting improvement of sports effectiveness (Cherapkina et al., 2012; Cherapkina, 2012; Strizhkova, O.U. et al., 2014), allowed for use by WADA. Works of the last years show activity of scientists on introduction of neurobiofeedback in process of training of athletes. In maintenance and achievement of a condition of optimum performance Silverman (2011) were engaged in studying of use of biofeedback and Todd T. (2011), Sherlin L. et al. (2011), Strack B. et al. (2011) other.

In works of Dupee et al. (2011-2016), Ford et al. (2016), Blumenstein and Orbach (2014) it is shown that neurobiofeedback in combination with biofeedback in other physiological parameters allows the athlete, including the top skills, to develop strategy of control and control of the main physiological mechanisms and further to use for achievement of an optimum functional state.

At the same time, authors emphasize the need of further carrying out researches for this field of knowledge, first of all, caused by insufficiently studied physiological mechanisms, small selections, limited number of the studied sports and big interindividual variability of indicators of EEG.

The purpose of the presented work was identification of features of bioelectric activity of the athletes brain taking into account gender distinctions, and determination of the importance of effects of neurobiofeedback in competitive activity effectiveness forecasting.

\section{RESEARCH METHODS AND ORGANIZATION}

Athletes of 22 sports specializations ( $n=101$ ), part of them has participated in a research: 26 people did acyclic nonstandard variables, 45 athletes did acyclic standard variables, 30 people did cyclic sports. Average age of the examined persons - $19 \pm 0,1$ years. Experience of sports activities is not less than 5 years. On sports qualification athletes were divided as follows: 3 athletes had a rank of the world class master of sports; a rank of the Master of Sports 24 persons have; 36 athletes are the candidate for the Master of Sports; 23 persons had the first adult category; the second adult category are 15 people. Among surveyed there were 59 young men, and 42 girls. Any violations of sexual differentiation haven't been revealed. All athletes gave the written agreement to participation in the research.

The course of neurobiofeedback directed to increase in power of EEG in the alpha range by Pogadaeva (2001) technique was conducted with each athlete by means of a hardware and software system of "BOSLAB-ALFA" (IMBB, Russia). Prior to training and after the termination at athletes in standard conditions (lying at the closed eyes) EEG by means of the 19-channel electroencephalograph "Neuron Range 3" was registered ("Neyrosoft", Russia), electrodes settled down according to the international scheme "10-20" (installation monopolar, reference electrodes - ear). The segment from 8 eras which are blocked for $50 \%$, of 1024 steps was analyzed. The studied characteristics of biopotentials of a brain were calculated for 16 assignments in four frequency ranges: the delta $(0,4-3,9 \mathrm{~Hz})$, a theta $(4,3-7,8 \mathrm{~Hz})$, an alpha $(8,2-12,9 \mathrm{~Hz}), \mathrm{a}$ beta $(13,3-19,9 \mathrm{~Hz})$ of activity (use of the term "activity" is caused by the fact that allocation of the studied 
component from EEG was carried out only on frequency sign (Zenkov, 1996). Record EEG of each of athletes was compared to "norm". As "norm" the record created by merge of the records EEG received at 50 students who weren't playing sports and not having pathology of neurologic type (Ravens et.al., 2003) was used. The examined athletes in the anamnesis also had no injuries and diseases of TsNS.

In addition at 52 athletes (24 young men and 28 girls) after a course of neurobiofeedback the effectiveness of competitive activity which was considered as successful was estimated if exceeded the result received at the previous competitions of the same rank.

The statistical analysis of the obtained data was carried out by means of software packages of "StatPack" and "SPSS 13". The nonparametric statistical test of Mann-Whitney is applied to assessment of probability of credibility of a hypothesis of uniformity of two selections (more precisely - equalities of medians). The discriminant analysis with a step-by-step method of Wilks has been used for identification of the factors defining efficiency of training.

\section{RESULTS}

The analysis of the obtained data has shown that higher power of bioelectric activity of a brain in comparison with "norm" is characteristic of overwhelming number of athletes: in the delta range in all studied assignments (fig. 1), in a theta - and beta ranges - in 14 assignments from 16 (statistically significant difference wasn't a theta range and $T_{4}, C_{4}$ of beta range only in assignments of $C_{4}, P_{3}$ ). Power in the alpha range tends to violation of typical topographical distribution. At athletes power in this range is higher in comparison with "norm" in forward areas of a brain (assignment of $\mathrm{Fp}_{1}, \mathrm{Fp}_{2}, \mathrm{~F}_{7}, \mathrm{~F}_{8}$ ) and the left temporal area (assignment of $T_{3}, T_{5}$ ) and below in right frontal (assignment of $F_{4}$ ) and central occipital areas of both hemispheres (assignment of $\mathrm{C}_{3}, \mathrm{C}_{4}, \mathrm{P}_{3}, \mathrm{P}_{4}, \mathrm{O}_{1}, \mathrm{O}_{2}$ ).

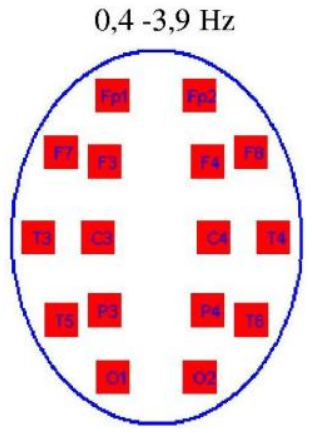

more than at norm
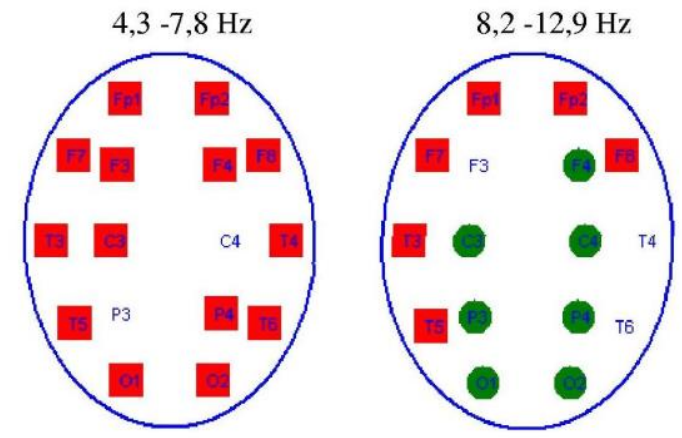

less than at norm

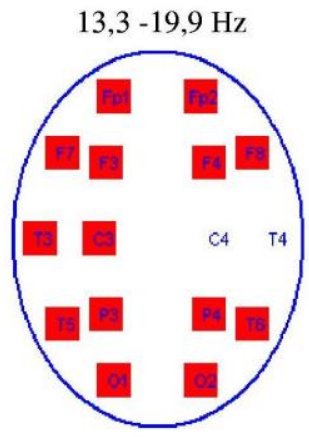

Fig. 1. Statistically significant distinctions $(\mathrm{P}<0,05)$ on an indicator of spectral power of EEG in

the studied frequency ranges between group of athletes and the "norms" group

The size of relative power of bioelectric activity of a brain in the delta range at athletes exceeded these "norms" practically on all assignments (an exception assignments of $\mathrm{Fp}_{2}, \mathrm{~F}_{8}, \mathrm{~T}_{4}, \mathrm{~T}_{6}$ have made) (fig. 2), in a theta range this indicator generally corresponded to data of "norm". The exception was made back temple area of the right hemisphere (assignment of $T_{6}$ ) in which at athletes higher relative power in a theta range, and frontal areas of the left hemisphere (assignment of $\mathrm{Fp}_{1}, \mathrm{~F}_{3}$ ) in which, on the contrary, the relative 
contribution of power in a theta range was below "norm" was more often observed. Relative power in the alpha range in the studied assignments (except for assignments: $F p_{2}, F_{8}, T_{4}$ ) at an overwhelming part of athletes was less "norm". In the beta range athletes were characterized by the smaller size of relative power in the left hemisphere (this difference only in assignments of $C_{3}$ and $P_{3}$ wasn't observed), and lack of statistically significant differences in comparison with the norms group in the right hemisphere (the exception has made assignment of $\mathrm{T}_{4}$ ).

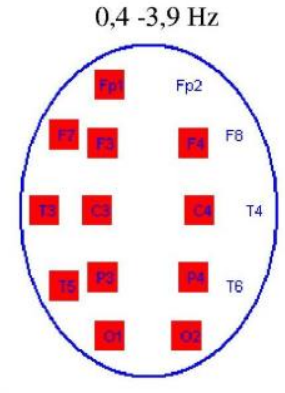

more than at norm

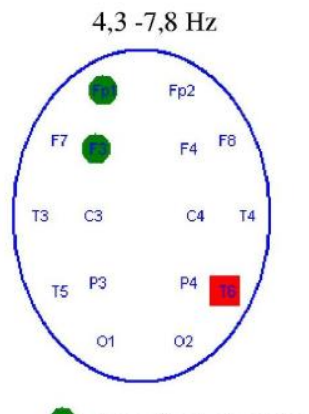

less than at norm
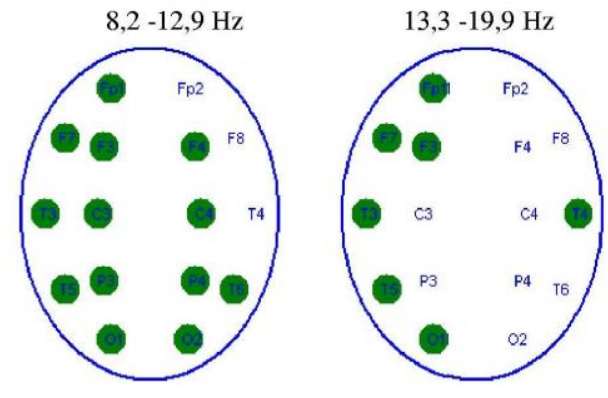

Fig.2. Statistically significant distinctions $(\mathrm{P}<0,05)$ on an indicator of relative spectral power of

EEG in the studied frequency ranges between group of athletes and the "norms" group

Frequency of waves of EEG at athletes in the studied ranges in the majority of assignments had no statistically significant distinctions with indicators of the norm group (fig. 3). There didn't correspond to this distribution lower sizes of average frequency in the delta range of left hemisphere of 6 to assignments $\left(F p_{1}\right.$, $F_{3}, T_{3}, C_{3}, P_{3}, O_{1}$ ), in a theta range in occipital area of both hemispheres (assignment of $O_{1}, O_{2}$ ), in the beta range in the left front temporal area and mid temporal areas of both hemispheres (assignment of $F_{7}, T_{3}, T_{4}$ ). In the alpha range frequency in the left back temporal area (assignment of $T_{5}$ ) has appeared above data of "norm".

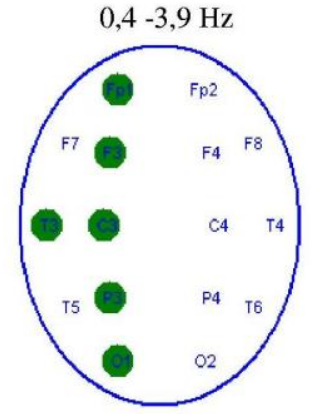

more than at norm

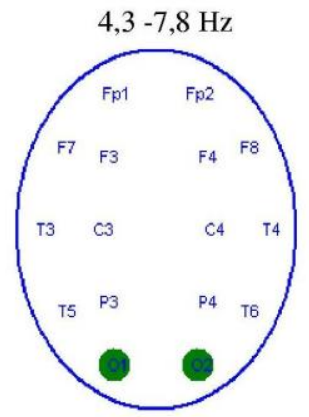

less than at norm
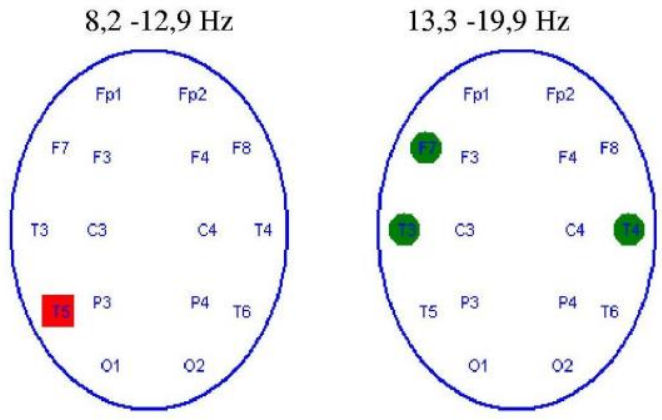

Fig. 3. Statistically significant distinctions $(\mathrm{P}<0,05)$ in size of average frequency of EEG in the studied ranges between group of athletes and the "norms" group

The analysis of integrated indicators of EEG has shown that athletes in all assignments, except for the right front forehead area (assignment of $\mathrm{Fp}_{2}$ ), had a size of the integrated index more "standard", and size of the 
age index in all registered assignments - there is less "norm" (fig. 4).

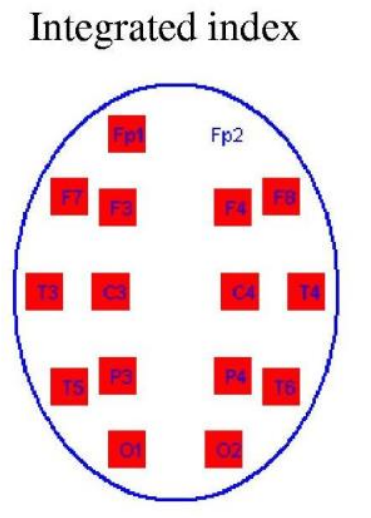

more than at norm
Age index

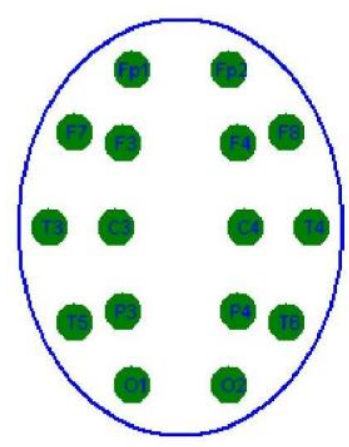

less than at norm

Fig. 4. Statistically significant distinctions $(\mathrm{P}<0,05)$ in sizes of integrated and age indexes between group of athletes and the "norms" group

One more distinctive feature of a pattern of EEG of athletes was easing of coherence of EEG that according to literary data (Tarasova et al., 2010) is sign of high creativity. At the same time diffusion reduction of level of coherence of EEG was observed at 36 of surveyed (fig.5A). At 50 athletes at the general lower level of coherent communications strengthening of interaction between left parietal $\left(\mathrm{P}_{3}\right)$ and right occipital $\left(\mathrm{O}_{2}\right)$ by areas (fig. 5B), as we know, providing the spatial organization of movements was observed.

A

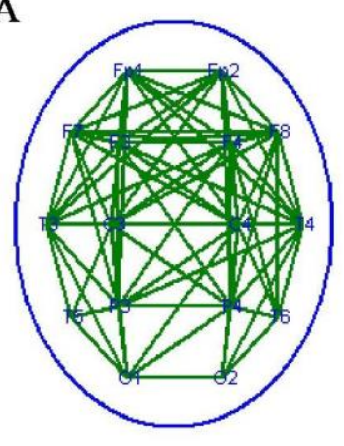

B

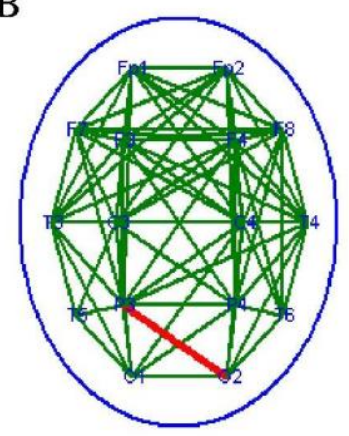

Fig. 5. Examples of manifestation of spatial interactions in EEG at athletes in comparison with "norm": "A" is a diffusion weakening of level of coherent communications; " $\mathrm{B}$ " is strengthening of coherent communication between assignments of $\mathrm{P}_{3}$ and $\mathrm{O}_{2}$ against the background of weakening of other interactions

In fact the organization of a brain at men and women from the earliest age goes on a different way (Danilova, 2012). For a further research all examined athletes have been divided into two groups: young men $(n=59)$ 
have made the first group, girls $(n=42)$ - the second.

Intergroup comparison of the obtained data has shown that the big size of spectral power of EEG in the right hemisphere and medial assignments (mainly parietal and occipital area) of the left hemisphere (fig. 6) is characteristic of sportswomen in comparison with athletes. At the same time with increase in frequency (from delta range to beta range) the number of assignments in which distinctions are observed increases.

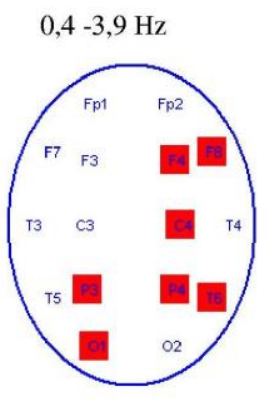

more than at first group
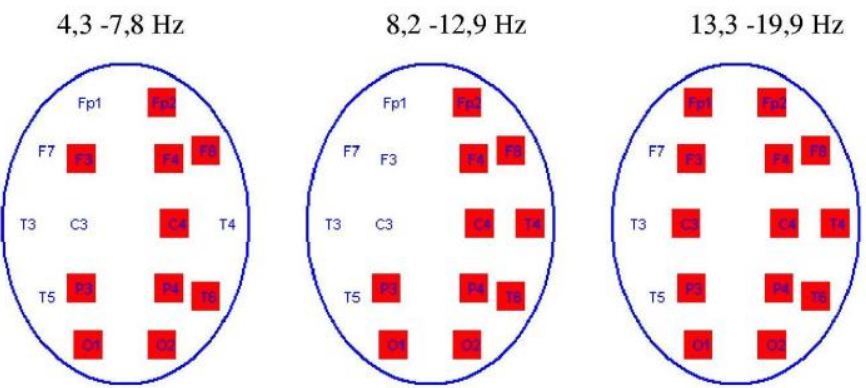

less than at first group

Fig. 6. Statistically significant distinctions $(\mathrm{P}<0,05)$ on an indicator of spectral power of EEG in the studied frequency ranges between the first and second groups of athletes

The contribution of the relative power (fig. 7) in the delta range practically in all assignments (an exception assignments of $\mathrm{T}_{4}, \mathrm{P}_{3}, \mathrm{O}_{2}$ have made) at girls has appeared less, than at young men, and in the beta range, on the contrary, - it is more (except for assignment of $\mathrm{P}_{4}$ ). In a theta - and alpha ranges of the girl differed from young men with a bigger size of relative power to 4 assignments ( $\mathrm{Fp}_{2}, \mathrm{~F}_{7}, \mathrm{~F}_{4}, \mathrm{~T}_{3}-$ in a theta range; $\mathrm{Fp}_{2}$, $\mathrm{C}_{4}, \mathrm{~T}_{3}, \mathrm{O}_{1}-$ in the alpha range).

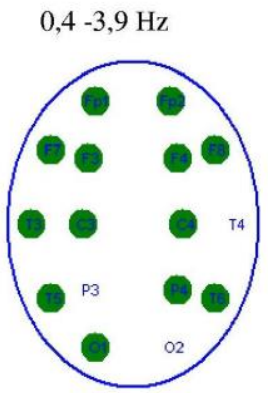

more than at first group
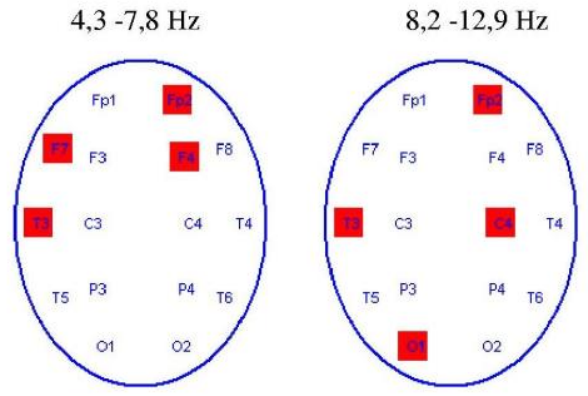

less than at first group

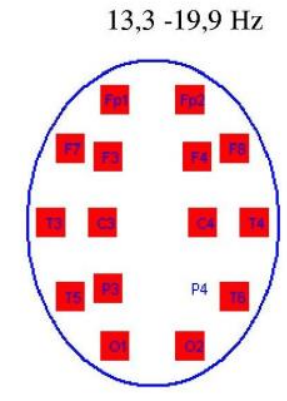

Fig. 7. Statistically significant distinctions $(\mathrm{P}<0,05)$ on an indicator of relative spectral power of

EEG in the studied frequency ranges between the first and second groups of athletes

Girls in comparison with young men had more expressed (mainly interhemispherical) coherence of fluctuations of EEG in the alpha range, especially in central occipital areas of a brain (fig. 8). Corsi-Cabrera et al. (1989) was also established that in a condition of relative rest the interhemispherical correlation in the 
alpha range of frequencies in the central, parietal and occipital assignments at women is higher, than at men. Statistically significant differences of this indicator in other ranges of frequencies between girls and young men haven't been revealed.

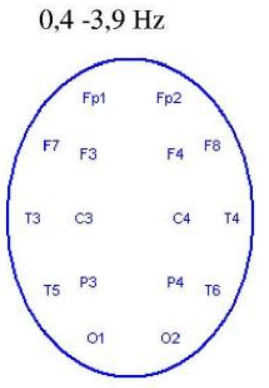

more than at first group
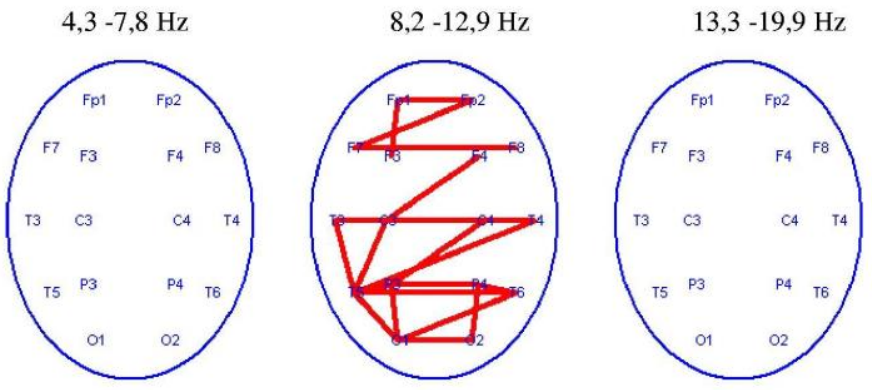

less than at first group

Fig. 8. Statistically significant distinctions $(\mathrm{P}<0,05)$ in size of coherence of $E E G$ in the studied

frequency ranges between the first and second groups of athletes

The analysis of average frequency in the studied ranges of frequencies has shown that in the girl's beta range differed in nothing from young men (fig. 9), and in the alpha range had higher frequency practically on all assignments (an exception assignments of $\mathrm{P}_{4}, \mathrm{O}_{2}$ have made). According to literature (Zenkov, 1996), the big frequency of an alpha rhythm at women is connected with higher psychometric rates. In Tumyalis's researches with coauthors (2010) it is shown that the frequency of an alpha rhythm is connected with specific features of experience of positive and negative emotions: individuals with a high individual frequency of alpha activity take memory traces easier, represent in imagination more distinctly and more intensively endure an emotional condition of joy, than anger.

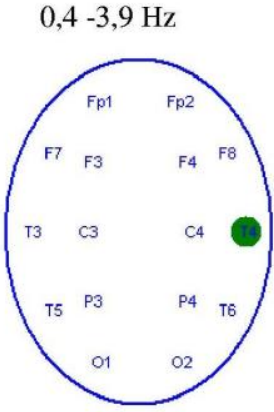

more than at first group
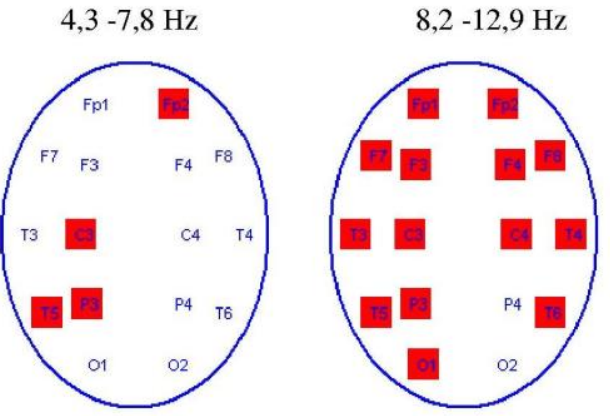

less than at first group
$13,3-19,9 \mathrm{~Hz}$

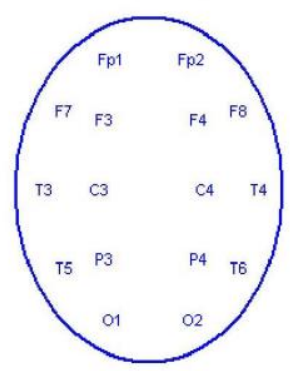

Fig. 9. Statistically significant distinctions $(\mathrm{P}<0,05)$ in size of average frequency of EEG in the studied ranges between the first and second groups of athletes

In a theta range at girls in comparison with young men big frequency in assignments of $\mathrm{Fp}_{2}, \mathrm{C}_{3}, \mathrm{P}_{3}, \mathrm{~T}_{5}$ was observed. According to Golubeva (2005), frequency the theta rhythm progressively increases at low levels of an activity and decreases at high. At the same time, Van Baal et al. (2001) was defined that heritability of 
EEG of characteristics in $\mathrm{C}_{3}$ and $\mathrm{P}_{3}$ assignments the theta range best of all speaks a genotype - the environmental model considering sexual distinctions.

In the delta range of the girl differed from young men in lower frequency only in one assignment $-\mathrm{T}_{4}$ which projection of cortical localization is connected with the field 22 across Brodman, known as the field Vernike. At the same time, according to Razumnikova and Bryzgalov (2005), women generate words more, than men.

The analysis of integrated indicators has shown that girls in comparison with young men were characterized by the smaller size of the integrated index in all studied assignments, except for assignment of $\mathrm{O}_{2}$, and distinctions in size of the age index hasn't been revealed (tab. 1).

Table 1

Intergroup distinctions of medians of the integrated and age EEG indexes (conventional unit.)

\begin{tabular}{|c|c|c|c|c|c|c|}
\hline \multirow{2}{*}{$\begin{array}{c}\text { Assignments } \\
\text { of EEG }\end{array}$} & \multicolumn{2}{|c|}{ Integral index } & \multirow[t]{2}{*}{$\mathrm{P}$} & \multicolumn{2}{|c|}{ Age index } & \multirow[t]{2}{*}{$\mathrm{P}$} \\
\hline & girls & young men & & girls & young men & \\
\hline $\mathrm{Fp}_{1}$ & 5,056 & 5,989 & $<0,02$ & 0,980 & 0,991 & $>0,05$ \\
\hline $\mathrm{Fp}_{2}$ & 4,399 & 5,527 & $<0,01$ & 1,069 & 1,078 & $>0,05$ \\
\hline $\mathrm{F}_{7}$ & 5,105 & 6,124 & $<0,01$ & 0,975 & 0,975 & $>0,05$ \\
\hline $\mathrm{F}_{8}$ & 4,603 & 5,785 & $<0,05$ & 0,993 & 1,038 & $>0,05$ \\
\hline $\mathrm{F}_{3}$ & 4,660 & 5,350 & $<0,02$ & 1,037 & 1,048 & $>0,05$ \\
\hline $\mathrm{F}_{4}$ & 5,224 & 5,964 & $<0,03$ & 0,984 & 0,986 & $>0,05$ \\
\hline $\mathrm{C}_{3}$ & 4,581 & 5,332 & $<0,05$ & 0,970 & 1,040 & $>0,05$ \\
\hline $\mathrm{C}_{4}$ & 5,059 & 6,058 & $<0,01$ & 0,946 & 0,955 & $>0,05$ \\
\hline $\mathrm{T}_{3}$ & 5,138 & 6,114 & $<0,01$ & 0,987 & 0,990 & $>0,05$ \\
\hline $\mathrm{T}_{4}$ & 4,612 & 5,684 & $<0,03$ & 0,992 & 1,007 & $>0,05$ \\
\hline $\mathrm{P}_{3}$ & 4,964 & 5,689 & $<0,05$ & 0,999 & 0,932 & $>0,05$ \\
\hline $\mathrm{P}_{4}$ & 5,785 & 6,878 & $<0,01$ & 0,903 & 0,936 & $>0,05$ \\
\hline $\mathrm{T}_{5}$ & 5,441 & 6,510 & $<0,02$ & 0,974 & 0,984 & $>0,05$ \\
\hline $\mathrm{T}_{6}$ & 5,278 & 6,160 & $<0,02$ & 0,944 & 0,938 & $>0,05$ \\
\hline $\mathrm{O}_{1}$ & 5,066 & 6,579 & $<0,00$ & 1,033 & 0,988 & $>0,05$ \\
\hline $\mathrm{O}_{2}$ & 4,990 & 5,688 & $>0,05$ & 0,971 & 0,991 & $>0,05$ \\
\hline
\end{tabular}

By the discriminant analysis it has been defined that at young men the success of competitive activity was defined by post-training sizes of absolute power in a theta range of the left temporal area (assignment of $T_{5}$ ) 
and also changes of values of the age index in temporal area of the right hemisphere (assignment of $\mathrm{T}_{6}$ ), absolute frequency in parietal area of the left hemisphere (assignment of $P_{3}$ ), coherence in $F_{3}-F p_{2}$, power in the delta and a theta range in average and temporal area of the left hemisphere (assignment of $\mathrm{T}_{3}$ ) and power in the alpha range in the right parietal area (assignment of $P_{4}$ ) (tab. 2). One discriminant function explaining $100 \%$ of dispersion has been received by a settlement way $\left(\chi^{2}=41,860 ; P<0,001\right)$, has made coefficient of initial correlation - 0,947. Accuracy of forecasting was $100 \%$. Average values of discriminant functions are presented in table 3.

Table 2

Coefficients of initial discriminant function * success of competitive activity at young men

\begin{tabular}{|c|c|c|}
\hline Data & Range and & Function \\
& assignment & \\
\hline absolute power $\left(\mathrm{mkv}^{2}\right)$ & $\theta\left(\mathrm{T}_{5}\right)$ & $-0,007$ \\
\hline size of change (delta) of power $\left(\mathrm{mkv}^{2}\right)$ & $\delta\left(\mathrm{T}_{3}\right)$ & 0,001 \\
\cline { 2 - 3 } & $\theta\left(\mathrm{T}_{3}\right)$ & $-0,030$ \\
\cline { 2 - 3 } & $\alpha\left(\mathrm{P}_{4}\right)$ & 0,007 \\
\hline size of change (delta) of coherence & $\mathrm{F}_{3}-\mathrm{Fp}_{2}$ & 37,900 \\
(conventional unit.) & & \\
\hline size of change (delta) of the age index \\
(conventional unit.) & $\mathrm{T}_{6}$ & 3,555 \\
\hline size of change (delta) of the absolute & & \\
\hline frequency (Hz) & $\mathrm{P}_{3}$ & $-3,697$ \\
\hline \multirow{2}{*}{ (Constant) } & & \\
\hline
\end{tabular}

Note: * Unrationed coefficients

Table 3

Values of discriminant function in centrodes of groups at young men

\begin{tabular}{|c|c|}
\hline Competitive activity & $\begin{array}{c}\text { Average values of } \\
\text { functions }\end{array}$ \\
\hline unsuccessful & $-3,973$ \\
\hline successful & 1,986 \\
\hline
\end{tabular}


At girls the success of competitive activity was defined by bigger association of post-training indicators: absolute and relative power in the alpha range of the right parietal area (assignment of $\mathrm{P}_{4}$ ); sizes of interspherical coherence mainly in forward areas of a cerebral cortex ( $F_{3}-F_{4}, F_{3}-F_{1}, F_{4}-F_{7}, F_{7}-T_{3}, F_{8}-F_{1}, O_{1}$ $T_{5}$ ); the size of the age index in the left parietal area (assignment of $P_{3}$ ); and also changes of relative power in the left hemisphere in delta range (assignment of $\mathrm{F}_{3}, \mathrm{O}_{1}, \mathrm{~T}_{3}$ ) and alpha range (assignment of $\mathrm{Fp}$ ); age (assignment of $\mathrm{C}_{3}$ ) and integrated (assignments of $\mathrm{O}_{1}, \mathrm{~T}_{5}$ ) indexes, coherence size in assignment of $\mathrm{C}_{4}-\mathrm{F}_{8}$ (tab. 4).

Table 4

Coefficients of initial discriminant function * success of competitive activity at girls

\begin{tabular}{|c|c|c|}
\hline Data & $\begin{array}{l}\text { Range and } \\
\text { assignment }\end{array}$ & Fuction \\
\hline absolute power $\left(\mathrm{mkv}^{2}\right)$ & $\alpha\left(\mathbf{P}_{4}\right)$ & $-0,300$ \\
\hline relative capacity $(\%)$ & $\alpha\left(\mathbf{P}_{4}\right)$ & 388,927 \\
\hline size of the age index (conventional unit.) & $\mathrm{P}_{3}$ & $-17,838$ \\
\hline \multirow[t]{6}{*}{ coherence of fluctuations of EEG } & $\mathrm{F}_{3}-\mathrm{F}_{4}$ & $-538,982$ \\
\hline & $\mathrm{F}_{3}-\mathrm{Fp}_{1}$ & 354,588 \\
\hline & $\mathrm{F}_{4}-\mathrm{F}_{7}$ & 251,215 \\
\hline & $\mathrm{F}_{7}-\mathrm{T}_{3}$ & 87,356 \\
\hline & $\mathrm{F}_{8}-\mathrm{Fp}_{1}$ & $-565,478$ \\
\hline & $\mathrm{O}_{1}-\mathrm{T}_{5}$ & $-36,663$ \\
\hline \multirow[t]{4}{*}{ size of change (delta) of relative power } & $\delta\left(\mathrm{F}_{3}\right)$ & 188,375 \\
\hline & $\delta\left(\mathrm{O}_{1}\right)$ & 45,798 \\
\hline & $\delta\left(\mathrm{T}_{3}\right)$ & 294,357 \\
\hline & $\alpha\left(\mathrm{Fp}_{1}\right)$ & 186,969 \\
\hline $\begin{array}{l}\text { size of change (delta) of coherence } \\
\text { (conventional unit.) }\end{array}$ & $\mathrm{C}_{4}-\mathrm{F}_{8}$ & 481,151 \\
\hline \multirow[t]{2}{*}{ size of change (delta) of coherence } & $\mathrm{O}_{1}$ & 1,747 \\
\hline & $\mathrm{T}_{5}$ & $-2,933$ \\
\hline $\begin{array}{l}\text { size of change (delta) of the age index } \\
\text { (conventional unit.) }\end{array}$ & $\mathrm{C}_{3}$ & 9,735 \\
\hline \multicolumn{2}{|l|}{ (Constant) } & 88,204 \\
\hline
\end{tabular}

Note: * Unrationed coefficients 
As a result of calculations at girls one discriminant function explaining $100 \%$ of dispersion has been received too $\left(\chi^{2}=122,650 ; P<0,001\right)$, has made coefficient of initial correlation $-1,000$. Accuracy of forecasting was $100 \%$. Average values of discriminant functions are presented in table 5 .

Table 5

Values of discriminant function in centrodes of groups at girls

\begin{tabular}{|c|c|}
\hline Competitive activity & $\begin{array}{c}\text { Average values of } \\
\text { functions }\end{array}$ \\
\hline unsuccessful & 36,989 \\
\hline successful & $-27,742$ \\
\hline
\end{tabular}

\section{DISCUSSION}

The researches conducted within the real work have allowed to reveal the special pattern of EEG inherent in the vast majority of athletes and characterized by more expressed activity in a theta - and delta ranges, the insufficient relative power of bioelectric activity of a brain in the alpha range, the absolute power, bigger in comparison with "norm", in the alpha range in forward areas of a brain (this feature has been noted also by other researchers working with athletes (Popova et al., 2006)), the low size of the age index, higher size of the integrated index and easing of coherence. Comparison of the obtained data with data of references, namely: manifestation of more expressed delta activity and an alpha rhythm, smaller on power, - with aggression (Fishbein et al., 1989 ); bigger expressiveness of an alpha rhythm in frontal assignments - with tendency to risky activity (Kudrin et al., 2014); rhythms a theta range - with motivation (Dubrovinskaya and Machinskaya, 2002), including with motivation of achievement as property of the personality (Konareva, 2009), selective attention (Basar-Eroglu and Demiralp, 2001; Machinskaya et al., 2016) and procedural memory (Klimesch, 1997); the reduced coherence - with independent data processing; the low size of the age index, - not only with turning on of brake mechanisms, but also, most likely, being based on the data of Gevins et al. (1997), Kamzanova (2011), and, in particular, Stroganova (2001), - with prevalence of endogenous attention, and higher size of the integrated index - with weakening of external influences due to creation of an internal cycle of work of neurons (Sokolov, 1969), - allows to speak about allocation of a peculiar " encephalographic portrait of the athlete" with "sports rage" inherent in him, ability to work in extreme conditions, abstraction if necessary from the environment, the result having high motivation on achievement and ability to expense of the maximum strong-willed efforts for achievement of the required purpose.

Specification of this "portrait" and its change in process of self-control with biological feedback, certainly, are individual and in many respects are defined by set of different factors, including sexual distinctions.

The bioelectric activity of a brain of sportswomen in comparison with athletes is characterized by higher frequency of an alpha rhythm, a large amount of beta activity, smaller size of the integrated index and more expressed coherence of fluctuations of EEG in the alpha range, especially in central occipital areas of a brain.

Keeping EEG the signs characteristic of women, sportswomen differ from sportsmen in set of post-training predictors of success of competitive activity. 
The possibility of competitive activities success forecasting for post-training indicators of EEG, in our opinion, will well be coordinated with methodology of system approach according to which in "usual conditions" (i.e. in conditions of relative rest) activity of integrative mechanisms "is hidden" in daily functioning of system. Neurobiofeedback, causing reorganizations of bioelectric activity of a brain, most likely, allows to open the intracerebral integrative processes (in the form of associations of informative indicators of post-training changes of EEG) determining distinctions by success of competitive activity of athletes of a different gender with an accuracy of recognition of $100 \%$.

\section{CONCLUSION}

The bioelectric activity of an athletes' brain is characterized by a number of the features forming a peculiar "the athlete's encephalographic portrait". In comparison with sportsmen the sportswoman have the smaller size of the integrated index, and they keep EEG the signs characteristic in general of women (higher frequency of an alpha rhythm, bigger amount of beta activity, more expressed coherence of fluctuations of EEG in the alpha range, especially in central occipital areas of a brain). Changes of certain sets of indicators of EEG during a neurobiofeedback course allow to predict rather precisely success of competitive activity both at girls, and at the young men playing sports.

\section{REFERENCES}

Basar-Eroglu C, Demiralp T. (2001). Event-related theta oscil- lations: An integrative and comparative approach in the human and animal brain // Int. J. Psychophysiol, 39. (2-3). 91-127. https://doi.org/10.1016/S0167-8760(00)00140-9

Blumenstein, B. Orbach I. (2014). Biofeedback for Sport and Performance Enhancement. http://www.oxfordhandbooks.com/view/10.1093/oxfordhb/9780199935291.001.0001/oxfordhb9780199935291-e-001

Cherapkina L.P., Strizhkova, O.U., Strizhkova, T.U. (2012). Neurofeedback in sport. Optimization of a functional condition of gymnasts. Palmarium Academic Publishing, 160.

Cherapkina, L.P. (2012). The neurofeedback successfulness of sportsmen Journal of human sport and exercise. University of Alicante. Special Issue; Supplementary Issue: 6th INSHS International Christmas Sport Scientific Conference, 11-14 December 2011, 7 (1), 116 - 127.

Corsi-Cabrera, M., Herrera, P., \& Malvido, M. (1989). Correlation between EEG and cognitive abilities: sex differences. International journal of Neuroscience, 45(1-2), 133-141. https://doi.org/10.3109/00207458908986226

Danilova N.N. (2012). Psychophysiology. M.: Aspect Press, 368.

Dubrovinskaya, N. V., \& Machinskaya, R.I. (2002). Reactivity a theta - and EEG alpha ranges at any attention at children of younger school age. Human physiology, 28(5), 15-20. https://doi.org/10.1023/A:1020266516114

Dupee, M., \& Werthner, P. (2011). Managing the stress response: The use of biofeedback and neurofeedback with Olympic athletes.Biofeedback, 39(3), 92-94. https://doi.org/10.5298/1081-5937$\underline{39.3 .02}$

Dupee, M., Forneris, T., \& Werthner, P. (2016). Perceived outcomes of a biofeedback and neurofeedback training intervention for optimal performance: Learning to enhance self-awareness and selfregulation with Olympic athletes. The Sport Psychologist,30(4), 339-349. http://dx.doi.org/10.1123/tsp.2016-0028 
Dupee, M., Werthner, P., \& Forneris, T. (2015). A preliminary study on the relationship between athletes' ability to self-regulate and world ranking. Biofeedback, 43(2), 57-63. http://dx.doi.org/10.5298/10815937-43.2.01

Fishbein, D.H., Herning, R.I., Pickworth, W.B., Haertzen, C.A., Hickey, J.E., \& Jaffe, J.H. (1989). EEG and brainstem auditory evoked response potentials in adult male drug abusers with self-reported histories of aggressive behavior. Biological Psychiatry, 26(6), 595-611. https://doi.org/10.1016/0006$\underline{3223(89) 90085-1}$

Ford, N. L., Wyckoff, S. N., \& Sherlin, L. H. (2016). Neurofeedback and mindfulness in peak performance training among athletes.Biofeedback, 44(3), 152-159. https://doi.org/10.5298/1081-5937-44.3.11

Gevins, A., Smith, M. E., McEvoy, L., \& Yu, D. (1997). High-resolution EEG mapping of cortical activation related to working memory: effects of task difficulty, type of processing, and practice.Cerebral cortex (New York, NY: 1991), 7(4), 374-385. https://doi.org/10.1093/cercor/7.4.374

Golubeva, E.A. (2005). Abilities. Personality. Identity. Dubna: "Phoenix +", 512.

Kamzanova, A. T., Matthews, G., Kustubayeva, A. M., \& Jakupov, S. M. (2011). EEG indices to time-ontask effects and to a workload manipulation (cueing). World Academy of Science, Engineering and Technology, 80, 19-22.

Klimesch, W., Doppelmayr, M., Schimke, H., \& Ripper, B. (1997). Theta synchronization and alpha desynchronization in a memory task. Psychophysiology, 34(2), 169-176. https://doi.org/10.1111/j.1469-8986.1997.tb02128.x

Konareva, I. N. (2009). Interrelation of features of the motivational sphere of the personality and characteristics of the current EEG. Neurophysiology, 41(1), 61-69. https://doi.org/10.1007/s11062009-9080-5

Kraynova, T.V., Berdichevskaya E.M. (2013). Functional profile of asymmetry in the young sportswomen, specializing in esthetic gymnastics. Bulletin of the Adygei state university. Series 4: Natural and mathematical and technical science, 2, 71-75.

Kudrin, R.A., Lifanova, E.V., Mironova, J.V. (2014). Typological features of intellect and bioelectrical activity of the brain in people who exhibit risk-seeking behaviour. Bulletin of the Volgograd state medical university, 3 (51), 62-65.

Machinskaya, R.I., Rozovskaya, R.I., Kurgan, A. V., \& Pechenkova, E. V. (2016). Cortical and cortical functional interaction at deduction of emotionally charged images in working memory. The analysis of coherence a theta rhythm ээг in space of sources. Human physiology, 42(3), 56-73. https://doi.org/10.1134/S0362119716020122

Pogodaeva, O.V. (2001). The predictors of the alpha-incentive training using efficiency in sports training: abstract of Ph.D. thesis. Tomsk, 19.

Popova, T. V., Koryukalov, Yu. I., \& Kourova, O. G. (2006). Variability of bioelectric activity of a brain at various conditions of athletes. Theory and practice of physical culture, (8), 20-22.

Ravens, V.G., Shchekutyev, G.A., Grindel, O.M. (2003). The software package for statistical comparison of records EEG. Materials of the international conference "Clinical neurosciences: neurophysiology, neurology, neurosurgery". Ukraine, Crimea, Gurzuf, 22-24.

Razumnikova, O. M., \& Bryzgalov, A. O. (2005). The frequency and spatial organization of electric activity of a brain at creative verbal thinking: floor factor role. The magazine of higher nervous activity of IP Pavlova, 55(4), 487-495.

Sherlin, L., Gervais, M., Talley, C., \& Walshe, A. (2011). Comprehensive sport performance program. Biofeedback, 39(3), 119-122. https://doi.org/10.5298/1081-5937-39.3.12

Silverman, S.J. (2011). Effecting Peak Athletic Performance with Neurofeedback, Interactive Metronome®, and EMDR: A Case Study. Biofeedback, 39 (1), 40-42. https://doi.org/10.5298/1081$\underline{5937-39.1 .08}$ 
Sokolov E. N. (1969). Memory mechanisms. M.: Mosk publishing house. un-that, 174.

Strack, B., Linden, M., \& Wilson, V. S. (Eds.). (2011). Biofeedback \& neurofeedback applications in sport psychology. Association for Applied Psychophysiology and Biofeedback, 410.

Strizhkova, O.U., Cherapkina L.P., Strizhkova, T.U. (2014). The neurofeedback course using of high skilled gymnasts at competitive period. Special Issue; Supplementary Issue: 8th INSHS International Christmas Sport Scientific Conference, 5-7 December 2013. Journal of human sport and exercise University of Alicante, 9(1), 561 - 569. https://doi.org/10.14198/jhse.2014.9.Proc1.47

Stroganova, T. A. (2001). Rhythms of EEG and development of processes of control of attention in babies: thesis... Dr.Sci.Biol.: 03.00.13. - Moscow, 323.

Tarasova I.V., Wolf N.V., Razumnikova O.M. (2010). Features of cortical interactions at persons with high and low verbal creativity. Human Physiology, 36 (1), 93 - 99. https://doi.org/10.1134/S036211971001010X

Todd, T. (2011). Improving Optimal Performance-And Life-For Young Athletes. Biofeedback, 39(3), 109111. https://doi.org/10.5298/1081-5937-39.3.08

Tregubova, M.V., Tarasov S.S. (2014). Dynamics of functional reactivity of the organism of athletes, depending on the nature, volume and intensity of training. Modern problems of science and education, 9(10), 2232-2235.

Tumyalis A.V., Korenek V.V., Braque I.V., Makhnev V. P., Reva N.V., Aftanas L.I. (2010). Individual frequency of alpha activity and experience of positive and negative emotions. The bulletin FROM the Russian Academy of Medical Science, 30(4), 132-142.

Van Baal, G. C. M., Van Beijsterveldt, C. E. M., Molenaar, P. C. M., Boomsma, D. I., \& De Geus, E. J. C. (2001). A genetic perspective on the developing brain: Electrophysiological indices of neural functioning in young and adolescent twins. European Psychologist, 6(4), 254-263. https://doi.org/10.1027//1016-9040.6.4.254

Zenkov, L.R. (1996). The clinic encephalography (with elements of the epilepsyology). Taganrog, 358.

This title is licensed under a Creative Commons Attribution-NonCommercial-NoDerivs 4.0 Unported License. 